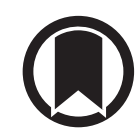

CrossMark

\title{
Exertional dyspnoea-ventilation relationship to discriminate respiratory from cardiac impairment
}

\author{
To the Editor:
}

Activity-related dyspnoea is a key cause of physical impairment in cardiovascular and respiratory diseases [1]. Despite remarkable diagnostic advances in the past decades, discriminating "the heart" versus "the lungs" as a cause of exertional dyspnoea remains a challenge for cardiologists and pulmonologists.

This state of affairs is not surprising if one considers that the respiratory neural drive, a key correlate of exertional dyspnoea, is characteristically increased in heart and lung diseases [2]. The differentiating feature, however, is the relative contribution of lung mechanical abnormalities as they are, by definition, more pronounced in the respiratory than in the cardiac patient [3]. Cardiopulmonary exercise testing (CPET) has long been advocated as the test of choice to determine the primary source of exercise limitation in these patients. In real life, however, there is substantial overlap in the physiological abnormalities underlying cardiovascular and respiratory diseases. It follows that CPET remains largely underused to untangle such a complex conundrum [4]. This scenario is partially explained by the fact that the interpretation of CPET in dyspnoeic patients remains heavily focused on physiological constructs. Although those physiological variables are important to objectively determine the biological basis of dyspnoea, it is surprising that little attention, if any, has been given to the symptom per se as an auxiliary diagnostic tool.

In this context, the burden of exertional dyspnoea can be readily quantified by expressing its severity (e.g. 0-10 Borg category-ratio scale) as a function of work rate (WR). The relationship between dyspnoea and ventilation $\left(V_{\mathrm{E}}^{\prime}\right)$, however, is more complex and may present with some discriminating features. Thus, if the ventilatory pump is free of major mechanical constraints (e.g. cardiocirculatory diseases), the increased drive to breathe can be largely translated into an equally high $V_{\mathrm{E}}^{\prime}$ [5]. In other words, the intensity and trajectory of dyspnoea as a function of $V^{\prime}{ }_{E}$ may not differ substantially from the pattern observed in normal subjects. Conversely, if the mechanical constraints typical of respiratory diseases preclude the ventilatory pump to "respond" to an increased drive, dyspnoea is expected to increase at a faster rate than $V_{\mathrm{E}}^{\prime}$ [6]. Owing to the fact that such constraints further increase beyond a certain critical intensity [7], it is conceivable that they could be identified by a sudden upward inflection of dyspnoea against $V_{\mathrm{E}}^{\prime}$. To the authors' knowledge, such theoretical constructs have not yet been put under scrutiny with the specific objective of discriminating cardiovascular versus respiratory disease as a cause of exertional dyspnoea.

In a proof-of-concept study, we enrolled two groups of patients: those in whom the cardiocirculatory derangements dominate over the lung mechanical abnormalities (chronic heart failure (CHF) with reduced left ventricular ejection fraction, $\mathrm{n}=14)$ and vice versa $(\mathrm{COPD}, \mathrm{n}=14)$. The control group consisted of 10 age- and gender-matched subjects free of cardio-respiratory disease. After standard pulmonary function tests, sensory (Borg dyspnoea and leg discomfort scores) and physiological responses (including oesophageal pressures and operating lung volumes) were assessed in an incremental CPET performed on a cycle ergometer. In order to obtain comparable groups as pertaining to exercise tolerance, the patient groups were carefully matched by peak WR and peak oxygen uptake ( $43 \pm 20$ versus $47 \pm 18 \%$ predicted and $65 \pm 18$ versus $63 \pm 17 \%$ predicted, respectively).

@ERSpublications

An upward inflection in dyspnoea versus both $V^{\prime}{ }_{E}$ and WR exposes lung mechanical abnormalities. Conversely, sharp increases in dyspnoea as a function of WR but not $V_{E}^{\prime}$ suggest that the underlying mechanism is proportional to inspiratory neural drive. http://bit.ly/2Ogapqr

Cite this article as: Plachi F, Balzan FM, Fröhlich LF, et al. Exertional dyspnoea-ventilation relationship to discriminate respiratory from cardiac impairment. Eur Respir J 2020; 55: 1901518 [https://doi.org/ 10.1183/13993003.01518-2019]. 

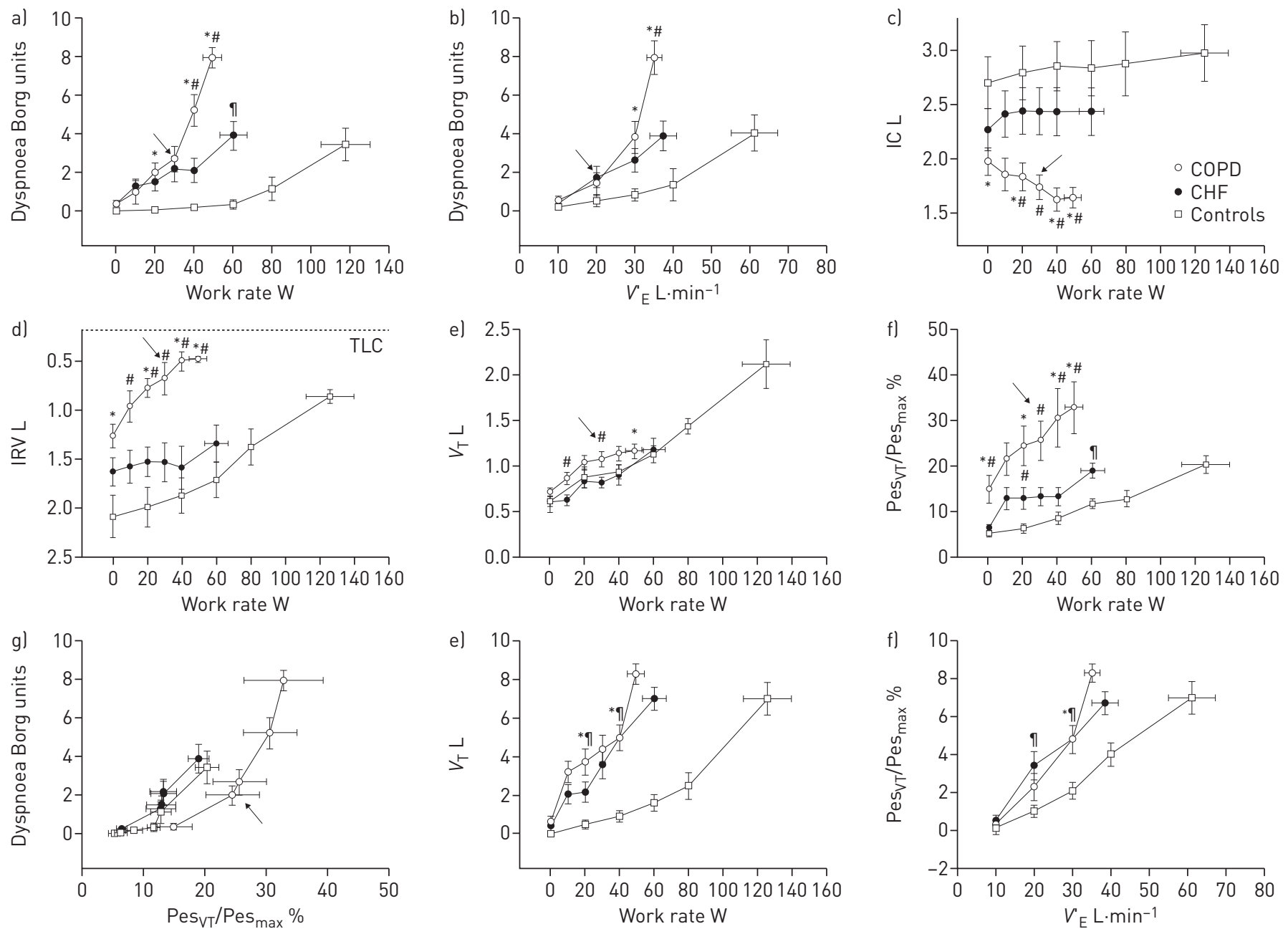

FIGURE 1 Dyspnea (a, b, g), ventilatory (c-e), mechanical (f, $g$ ) and leg discomfort ( $h$, i) responses to incremental exercise in subjects with cOPD, chronic heart failure (CHF) and age- and gender-matched controls. The arrows indicate the changes in physiological responses associated with the upward inflection in dyspnoea against minute ventilation $\left(V^{\prime}{ }_{E}\right)$ found in the COPD group (b). Values are presented as mean \pm SEM. Generalised estimated equation model with Bonferroni adjustments was used for between group comparisons. *: $p<0.05$, COPD versus controls; ${ }^{\#}$ : $p<0.05$, COPD versus CHF; ${ }^{\uparrow}: p<0.05$, CHF versus controls at standardised submaximal or peak work rate. IC: inspiratory capacity; IRV: inspiratory reserve volume; TLC: total lung capacity; $V_{\mathrm{T}}$ : tidal volume; PesVT: tidal oesophageal pressure; Pes max: maximal oesophageal pressure.

As expected, COPD patients presented with lower spirometric values (forced expiratory volume in $1 \mathrm{~s} 37$ \pm 12 versus $78 \pm 17 \%$ predicted) and transfer factor but higher static lung volumes and left ventricle ejection fraction $\left(67 \pm 6\right.$ versus $30 \pm 6 \%$ ) compared to $\mathrm{CHF}(\mathrm{p}<0.05)$. On exercise, $V_{\mathrm{E}}^{\prime}$ at a given WR was consistently higher in patients compared to controls (by $\left.\sim 5 \mathrm{~L} \cdot \mathrm{min}^{-1}\right)(\mathrm{p}<0.05)$. Dyspnoea-WR relationship was upwardly displaced in patients, particularly in those with COPD (figure 1a). On the other hand, dyspnoea- $V_{\mathrm{E}}^{\prime}$ relationship did not differ among the groups in the early phases of exercise. After $\sim 20 \mathrm{~L} \cdot \mathrm{min}^{-1}(\sim 30 \mathrm{~W})$, however, dyspnoea increased in excess to $V_{\mathrm{E}}^{\prime}$ in COPD, i.e. there was a discernible upward inflection in the dyspnoea- $V_{E}^{\prime}$ relationship (figure $1 \mathrm{~b}$ ). The upward inflection point in dyspnoea$V^{\prime}$ E relationship coincided with downward and upward variations in inspiratory capacity and inspiratory reserve volume (IRV) towards their lowest and highest values, respectively (figure 1c and d, respectively). Moreover, tidal volume plateaued (figure 1e) and oesophageal pressures further increased thereafter in the COPD group (figure 1f) $(\mathrm{p}<0.05)$. Interestingly, dyspnoea for a given inspiratory effort was not significantly different among the three groups (figure 1g), whilst leg effort was significantly higher in patients compared to controls both at isowork (figure 1h) and isoventilation (figure 1i).

We confirmed our hypothesis that, by plotting exertional dyspnoea ratings against WR and $V_{E}^{\prime}$, further information would be gained vis $\dot{a}$ vis the discrimination of cardiocirculatory (CHF) from mechanical-ventilatory (COPD) mechanisms of dyspnoea. Thus, the emergence of a key determinant of dyspnoea, severe inspiratory constraints at high operational lung volumes [8], coincided with an upward 
inflection in dyspnoea as a function of $V_{\mathrm{E}}^{\prime}$ only in the COPD group. Thereafter, dyspnoea increased at a faster rate than $V_{E}^{\prime}$ because the expected increase in inspiratory drive [9] could not be translated into an equally high $V_{\mathrm{E}}^{\prime}$ in the setting of a critically low IRV (figure 1b). As patients with CHF and controls breathed at low lung volumes, they did not present with such constraints (figure $1 \mathrm{c}$ and $\mathrm{d}$ ); accordingly, dyspnoea increased at an effectively linear function of $V_{E}^{\prime}$ in these subjects (at least up to the respiratory compensation point to acidosis in controls) (figure 1b).

Recent advances in the neurobiology of exertional dyspnoea provide a conceptual framework in which to interpret our results [1]. The key clinical challenge is to tease out whether an increased dyspnoea-WR relationship merely reflects a commensurate increase in the respiratory pump's output (i.e. $V_{\mathrm{E}}^{\prime}$ ) or, conversely, an out-of-proportion increase in dyspnoea relative to the output [10]. The latter scenario is consistent with the development of limiting mechanical abnormalities precluding an appropriate increase in $V_{\mathrm{E}}^{\prime}$ despite a heightened respiratory neural drive. Thus, an upward inflection of dyspnoea versus $V_{\mathrm{E}}^{\prime}$ indicates that the emergence of critical inspiratory constraints (figure $1 \mathrm{c}$ and $\mathrm{d}$ ) in conjunction with exaggerated inspiratory effort (figure 1f) does trigger intolerable respiratory sensations (figure $1 \mathrm{~g}$ ), which ultimately decrease patients' tolerance to exertion [11]. This means that despite differences in (patho) physiology, dyspnoea intensity during exercise in all three groups increased in association with increasing respiratory effort exacerbated by the incapacity to further expand the tidal volume [9].

What is the clinical implication of our results? In practice, relying only in discrete peak exercise ratings might be particularly misleading: dyspnoeic patients are usually not prepared to exercise beyond certain limits of comfort and/or the burden of peripheral symptoms (leg discomfort) may obscure the relevance of dyspnoea [12]. Moreover, they may present a similar leg discomfort perception pattern compared to subjects with typical cardiocirculatory limitation to exercise (figure $1 \mathrm{~h}$ and $\mathrm{i}$ ). In this context, dyspnoea$\mathrm{WR}$ and dyspnoea- $V_{\mathrm{E}}^{\prime}$ plots, if interpreted in conjunction with physiological responses, might prove valuable. Thus, a steep increase in dyspnoea as a function of both $\mathrm{WR}$ and $V_{\mathrm{E}}^{\prime}$ (or an inflection in dyspnoea- $V_{E}^{\prime}$ after a linear phase) points out for a major contributory role for abnormal lung mechanics, as expected in respiratory patients. Conversely, a sharp increase in dyspnoea as a function of WR but not $V_{\mathrm{E}}^{\prime}$ suggests that the underlying mechanism is rather proportional to the drive and not critically influenced by lung mechanics, e.g. increased chemosensitivity and ergorreceptor/sympathetic overactivation in a cardiac patient [13].

As expected from a proof-of-concept study, we contrasted patients in whom the seeds of dyspnoea are characteristically different. Thus, it is important that our findings be confirmed (or negated) in patients with combined physiological abnormalities, e.g. mechanical constraints plus increased chemosensitivity. Of note, we previously found that a preserved (i.e. compared to controls) dyspnoea- $V_{\mathrm{E}}^{\prime}$ relationship showed a discernible upward inflection only in patients with COPD-CHF overlap who reached critical inspiratory constraints [14]. To be used in practice, frames of reference for dyspnoea-WR and dyspnoea- $V^{\prime}{ }_{\mathrm{E}}$ are, of course, required (the comprehensive prediction values established by KiLLIAN et al. [15] are recommended while other normative values are not available) and this approach validated in future studies investigating dyspnoeic subjects without a previously known mechanism.

In conclusion, whereas the overall burden of exertional dyspnoea secondary to cardiac or lung disease can be readily obtained from the dyspnoea-WR relationship, an increase (or an upward inflection) in dyspnoea as a function of $V_{E}^{\prime}$ exposes lung mechanical abnormalities which are characteristically more relevant in the respiratory than in the cardiac patient.

Franciele Plachi ${ }^{1,3}$, Fernanda Machado Balzan ${ }^{1,3}$, Luiz Felipe Fröhlich ${ }^{1}$, Ricardo Gass ${ }^{1}$, Nathalia Branco Mendes ${ }^{1}$, Elisa Schroeder ${ }^{1}$, Danilo C. Berton $\oplus^{1}$, Denis E. O’Donnell $\oplus^{2}$ and J. Alberto Neder $\oplus^{2}$

${ }^{1}$ Programa de Pós-Graduação em Ciências Pneumológicas, Universidade Federal do Rio Grande do Sul/Hospital de Clínicas de Porto Alegre, Porto Alegre, Brazil. ${ }^{2}$ Laboratory of Clinical Exercise Physiology, Kingston Health Science Center and Queen's University, Kingston, ON, Canada. ${ }^{3}$ These authors contributed equally to the study.

Correspondence: J. Alberto Neder, Laboratory of Clinical Exercise Physiology and Respiratory Investigation Unit, Queen's University and Kingston General Hospital, 102 Stuart Street, Kingston, ON, K7 L 2V6, Canada. E-mail: alberto. neder@queensu.ca

Received: 31 July 2019 | Accepted after revision: 11 Nov 2019

Conflict of interest: None declared.

Support statement: This work was supported by Conselho Nacional de Desenvolvimento Científico e Tecnológico (476356/2013) and Incentive Fund of Research of Hospital de Clinicas de Porto Alegre (HCPA/Brazil (14-0041, 14-0512). Funding information for this article has been deposited with the Crossref Funder Registry. 


\section{References}

1 Mahler DA, O'Donnell DE. Recent advances in dyspnea. Chest 2015; 147: 232-241.

2 Neder JA, Rocha A, Alencar MCN, et al. Current challenges in managing comorbid heart failure and COPD. Expert Rev Cardiovasc Ther 2018; 16: 653-673.

3 Dubé B-P, Agostoni P, Laveneziana P. Exertional dyspnoea in chronic heart failure: the role of the lung and respiratory mechanical factors. Eur Respir Rev 2016; 25: 317-332.

4 Neder JA, Laveneziana P, Ward SA, et al. Introduction: CPET in clinical practice. Recent advances, current challenges and future directions. In: Palange P, Laveneziana P, Neder JA, et al., eds. Clinical Exercise Testing (ERS Monograph). Sheffield, European Respiratory Society, 2018; pp. x-xxv.

5 O'Donnell DE, Elbehairy AF, Berton DC, et al. Advances in the evaluation of respiratory pathophysiology during exercise in chronic lung diseases. Front Physiol 2017; 8: 82.

6 O'Donnell DE, Laveneziana P. Dyspnea and activity limitation in COPD: mechanical factors. COPD 2007; 4 225-236.

7 O'Donnell DE, Laveneziana $\mathrm{P}$, Webb $\mathrm{K}$, et al. Chronic obstructive pulmonary disease: clinical integrative physiology. Clin Chest Med 2014; 35: 51-69.

8 O'Donnell DE, Elbehairy AF, Faisal A, et al. Exertional dyspnoea in COPD: the clinical utility of cardiopulmonary exercise testing. Eur Respir Rev 2016; 25: 333-347.

9 Faisal A, Alghamdi BJ, Ciavaglia CE, et al. Common mechanisms of dyspnea in chronic interstitial and obstructive lung disorders. Am J Respir Crit Care Med 2016; 193: 299-309.

10 O'Donnell DE, Ora J, Webb KA, et al. Mechanisms of activity-related dyspnea in pulmonary diseases. Respir Physiol Neurobiol 2009; 167: 116-132.

11 Laveneziana P, Webb KA, Ora J, et al. Evolution of dyspnea during exercise in chronic obstructive pulmonary disease: impact of critical volume constraints. Am J Respir Crit Care Med 2011; 184: 1367-1373.

12 Pepin V, Saey D, Whittom F, et al. Walking versus cycling: sensitivity to bronchodilation in chronic obstructive pulmonary disease. Am J Respir Crit Care Med 2005; 172: 1517-1522.

13 Dempsey JA, Smith CA. Pathophysiology of human ventilatory control. Eur Respir J 2014; 44: 495-512.

14 Rocha A, Arbex FF, Sperandio PA, et al. Excess ventilation in COPD-heart failure overlap: implications for dyspnea and exercise intolerance. Am J Respir Crit Care Med 2017; 196: 1264-1274.

15 Killian KJ, Summers E, Jones NL, et al. Dyspnea and leg effort during incremental cycle ergometry. Am Rev Respir Dis 1992; 145: 1339-1345. 